\title{
Direitos humanos: utopia num mundo distópico?
}

\author{
Cândido Alberto Gomesi \& Adriana Liraii \\ Universidade Católica de Brasília, Brasil
}

\begin{abstract}
Resumo
Este artigo indaga se os direitos humanos seriam parte de uma utopia da modernidade, que se desvanecem ante distopias e desafios da sociedade contemporânea. Analisando a trajetória histórica dos direitos humanos, verificase que se compõe de períodos de emergência e latência. Uma visão da situação atual evidencia significativos avanços no que se refere às normas, monitoramento, denúncia e consciência dos mesmos, apesar das contradições, especialmente entre as normas e sua aplicação pelos Estados nacionais soberanos. A literatura sugere que tais avanços se devem menos às sanções que à consciência em face da legitimidade moral dos direitos humanos, o que ressalta a importância da educação, tanto escolar como extraescolar. No que tange à escola, requer transformações profundas: conhecer melhor os educandos e construir clima baseado no exemplo da prática e respeito dos direitos humanos. Os currículos precisam abranger a interdisciplinaridade e métodos que incentivem a atuação dos alunos como protagonistas.
\end{abstract}

Palavras-chave

Direitos humanos; Educação para os direitos humanos; Currículos; Modernidade

\section{Introdução}

Seriam os direitos humanos parte de uma utopia em processo de gradual construção? Ou seriam um norte ilusório a contrastar com distopias 
que dariam sinais de encarnar na realidade? Estariam os direitos humanos sendo arrastados por um processo de estilhaçamento de certezas e de usurpação de falsas certezas? Em ambos os casos, a educação, que tende a confirmar o status quo, teria um papel relevante a desempenhar, ou, no caso especialmente da educação escolar, estaria em dissintonia crescente com a vida daqueles que dela participam? Ou seriam a educação e os direitos humanos relíquias arqueológicas de uma modernidade que passou? Para buscar algumas trilhas, este trabalho se divide em três partes, desembocando nas conclusões: 1) Entre alvoreceres e crepúsculos históricos, os direitos humanos tenderiam a desvanecer-se? 2) Considerando-se que a comunicação intergeracional está submetida a filtros de esquecimento e lembrança da cultura, que perspectivas teriam as novas gerações? Por fim, seria viável a educação para os direitos humanos? E, para viabilizar-se, qual o esboço das suas principais características?

\section{Entre utopias e distopias}

Não é de hoje que se constroem sociedades imaginárias, com objetivo crítico em face da realidade vigente. A fogueira e outros meios, porém, não pouparam em certos casos os seus autores. Além delas, também têm sido desenhadas distopias, ou anti-utopias, a alertar contra os riscos de situações altamente indesejáveis, cabendo mencionar, entre outras, 1984, de Orwell (2011), Admirável mundo novo, de Huxley (1998), e os filmes Alphaville (1965), de Goddard, e o atualíssimo Gattaca (1997), de Niccol. As distopias desmentem a confiança nos caminhos do progresso e do desenvolvimento, guiados pela estrela do contínuo aperfeiçoamento do homem, das certezas e das visões explicativas abrangentes, que reduziam a complexidade à relativa simplicidade de algumas teorias. As perspectivas modernas se dissolveram, as certezas se derreteram, enquanto muitos valores caíram em águas turvas e os poucos centros gravitacionais se dispersaram numa multidão. $\mathrm{O}$ aclive contínuo de uma ou algumas vias rumo ao horizonte do progresso se esfumou como ilusório. Estariam os direitos humanos, então, reduzidos à ficção?

Ante pergunta de difíceis respostas categóricas, cumpre lembrar perspectivas científicas que, como lentes, sintetizam visões da sociedade hoje, salientando características e processos e assinalando os desdobramentos da modernidade ou, ainda, a traçar-Ihes uma fronteira que a 
princípio não diz muito, a pós-modernidade, ou seja, a que sucede à modernidade (Gomes, 2005). Dentre elas se destacam a modernidade tardia (Giddens, 1991), a modernidade líquida (Bauman, 2003) e a sociedade de risco (Beck, 2009). Detenhamo-nos brevemente nesta última. A interdependência do mundo, com a compressão do tempo e do espaço, contribui para que as decisões civilizatórias causem consequências globais geradoras de problemas e perigos que contradizem radicalmente a linguagem institucionalizada e as promessas das autoridades em situações catastróficas no mundo inteiro, como Chernobyl, os atentados de 11 de setembro, as mudanças climáticas e a insustentabilidade do desenvolvimento predatório. Num período em que a fé em Deus, na classe, nação ou governo está desaparecendo, conforme Beck, a reconhecida natureza global do perigo se torna uma fusão de relações em que as aparentes constantes do mundo político subitamente derretem e se tornam maleáveis. O multilateralismo é uma resposta necessária, mas que em parte contradiz o caráter dos Estados nacionais e sua soberania. Este nó górdio também envolve os direitos humanos, concebidos e estatuídos multilateralmente, mas dependentes, para o seu cumprimento, de cada Estado-membro, signatário (ou não) das suas convenções, imunes a intervenções multilaterais.

No cenário da sociedade de risco, detecta-se ainda outra contradição, por meio das catástrofes: o contraste entre a fascinação pelo poder técnico e o terror por um futuro em que se leem promessas de declínio (Vidal, 2012). O homem comum capta essa atmosfera pela mediatização, no mercado do medo, a compor uma paisagem tecida pela concatenação de acidentes. Conforme Vidal, num universo desencantado, onde a queda se torna a regra e não há redenção, faltam valores, hierarquias e julgamentos possíveis. Se, de um lado, a ciência e a técnica modernas permitem melhor compreender o mundo e prevenir riscos e catástrofes, por outro, se situa o desencantamento do mundo, com a falta de sentido da morte, do fim (do mundo) e da vida. Impõe-se, assim, a necessidade de uma nova relação com a realidade. Neste contexto centrífugo, inclusive diante de ameaças terroristas transnacionais e da desafiante conciliabilidade entre o medo e a preservação da privacidade, os direitos humanos mais parecem chamas bruxuleantes ao vento, haja vista os vazamentos de crimes de guerra e do colossal controle de informações por governos, com as implicações geopolíticas da sua criminalização. Os 
denunciantes, indivíduos empoderados em face do Estado, seriam traidores ou heróis? Desse modo, a modernidade, responsável pelo desabrochar da individualidade e dos correspondentes direitos humanos, que se desdobraram em direitos econômicos e sociais, trair-se-ia a si mesma no mundo em risco. Em outras palavras, como os fins justificariam os meios, o controle hobbesiano dos indivíduos seria uma suposta imposição para a sobrevivência da liberdade. É como se um regime fosse tão democrático que proibisse manifestações antidemocráticas...

\section{Direitos humanos: entre auroras e crepúsculos}

Os caminhos históricos dos direitos humanos mostram que estes apareceram em ordem dispersa, primeiro no direito interno dos Estados. Constituem alguns dos seus marcos a Grande Carta concedida por João sem Terra (1215), o Bill of Rights (1628) da Grã-Bretanha, o Habeas Corpus (1679), a Declaração de 1787 dos Estados Unidos e a Declaração dos Direitos do Homem e do Cidadão (1789) da França (Delmas-Marty, 2004). Porém, constata-se um longo hiato de entre as Revoluções Americana e Francesa e a vigente Declaração Universal dos Direitos Humanos (1948) (Hunt, 2007). A espessa noite deste intervalo foi marcada pela explosão de explicações biológicas das diferenças, que 'justificaram' os racismos, o sexismo e o antissemitismo, entre outros, e pela ascensão do nacionalismo após 1815. No entanto, como nota Hunt (2007), embora os direitos naturais universalmente aplicáveis não avançassem, os direitos continuaram a ser conquistados nacionalmente, como os dos trabalhadores, das mulheres e das minorias. Foram as sociedades benevolentes que mantiveram a chama acesa por século e meio.

De fato, a ação nacional e internacional de pessoas e grupos não deve ser subestimada, como Appiah (2010) constata na análise comparativa de várias revoluções morais, contra o duelo, a deformação dos pés das mulheres chinesas, a escravidão atlântica e as guerras contra as mulheres. Nos três primeiros casos, o código de honra (honra para defender uns, mas que atentava contra a honra de outros, por exemplo, não exercer o trabalho manual à custa da desonra da escravidão) que as fundamentava foi contestado pela moral e religião, levando a honra a alinhar-se com a moralidade. Os argumentos morais, que já existiam, encontraram o novo 
desejo de aplicá-los, levando ao envergonhamento coletivo e à desonra pública internacional, por meio da coalizão de grupos internos e externos. A internacionalização progressiva levou a ver uma prática de honra em outra parte do mundo como desrespeitosa a todas as pessoas, por meio da estratégia da 'afiliação simbólica'. Ou seja, o homem livre da Inglaterra sentiase ofendido quando seu semelhante era arrancado à África e coagido ao trabalho escravo no Caribe. Diríamos que a capacidade de colocar-se no lugar do outro e de importar-se com o outro (em coerência com o papel crucial de amar ao próximo como a si mesmo - Bauman, 2008) foi o germe de revoluções morais sem sangue que conquistaram a deslegitimação geral do que era considerado legítimo pelos seus beneficiários. O direito mais amplo, embora por caminhos tortuosos, acabou por levar a palma sobre o direito parcial dos opressores sobre os oprimidos. Podemos reconhecer nos processos analisados o esboço da cidadania planetária (Morin, 2001), pautada pelo valor universal da igualdade do ser humano. Um dos propulsores da defesa dos direitos humanos é a constituição das sociedades em rede (Castells, 2003), que ensejam esse envergonhamento público internacional, como frisa Appiah (2010).

Num processo de ampliação dos cenários históricos, as tragédias das duas guerras mundiais, conforme Hunt (2007), foram marcos na busca de novas soluções para a paz. No tratado com a Alemanha em 1918 a Rússia perdera quase dois milhões de homens. Quando acabou o que nossos antepassados chamavam de a Grande Guerra, no front ocidental 14 milhões de pessoas tinham morrido, a maioria soldados. Três quartos dos homens mobilizados para lutar na Rússia e França terminaram feridos ou mortos. Não bastasse este morticínio, no encerramento da Segunda Guerra Mundial havia 60 milhões de mortos, a maioria civis. Isso, porém, ainda não foi suficiente. As potências aliadas em 1945 procuravam 'melhorar' a Liga das Nações, mas a princípio rechaçaram as propostas de direitos humanos. Assinala Hunt (2007) que as pressões se originaram de médias potências latino-americanas e asiáticas, entre elas o Brasil, a braços com a liquidação de uma ditadura direitista, preocupadas com a "mão pesada" das grandes potências. A Declaração só veio a ser aprovada em 1948, depois de 83 encontros da Comissão presidida por Eleanor Roosevelt, quando a União Soviética e a GrãBretanha se asseguraram de que as Nações Unidas nunca interviriam nos 
assuntos internos de um país. Criou-se, pois, uma casa com grandioso telhado, mas frágil de alicerces, que, apesar de tudo, disseminou a constitucionalização dos direitos humanos (incorporação dos direitos humanos às constituições dos Estados) durante os decênios seguintes.

\section{Contradições estratégicas}

Os dramas e as tragédias da violação dos direitos humanos fluem de algumas contradições decorrentes deste processo histórico e de desdobramentos contemporâneos:

a) Obrigações morais e jurídicas $x$ carência de mecanismos de execução: Proclamam-se obrigações morais e jurídicas, por meio de numerosos atos e declarações, que podem ser ratificados ou não pelos Estados-membros das Nações Unidas, porém faltam mecanismos de execução no âmbito da soberania nacional. Este contraste pode subtrair legitimidade e gerar descrédito pelo contraste entre os valores proclamados e os valores vividos. Apesar das suas origens nacionais, os direitos humanos sofrem 0 hiato entre as normas internacionais e a dependência de Estados territoriais soberanos para sua execução (Donnelly, 2010). Como observado acima, o princípio da não intervenção e a predominância da soberania nacional num mundo global se situam na raiz desta dificuldade. Com isso, a questão precisa ser tratada ao nível da legitimidade moral, das denúncias e críticas, dos estímulos e desestímulos, como o envergonhamento público e global.

b) Estados nacionais $x$ organizações não governamentais: Enquanto cabe aos primeiros a execução, as últimas exercem um papel moral da maior relevância ao atuarem no campo da legitimidade, monitorando o exercício dos direitos humanos e suas violações. Entretanto, os Estados têm o poder de coagir total ou parcialmente tais organizações, inclusive nas suas relações com o mundo exterior.

c) Comunicação ampliada e globalizada $x$ mercado midiático do sensacionalismo: O mundo global, cada vez mais interdependente, apresenta teias entrelaçadas de comunicação que atuam à 
velocidade da luz. A mídia tem um papel extremamente importante na denúncia e acompanhamento de casos de violação dos direitos humanos; todavia, pode resvalar para o sensacionalismo, incentivado pelo mercado de audiência. Situados em arenas políticas, muitas vezes não democráticas, grandes e pequenos grupos de comunicação podem criar filtros, pautando ou não certas questões, com diferentes graus de ênfase e períodos desiguais. Todavia, como ressalta Castells (2009), se tais grupos dispõem de grande poder, os meios alternativos de comunicação podem servir a interesses opostos aos estabelecidos, conduzindo, inclusive, a processos de ampla mobilização popular, como a "primavera árabe" e as manifestações no Brasil.

d) Propagação rápida de fatos $x$ lentidão das cortes e outros órgãos governamentais: Quanto maior a exposição de violações pelos meios de comunicação, maior a expectativa de que elas sejam adequadamente tratadas. Contudo, o contraste entre a agilidade das redes e a inércia das organizações burocráticas piramidais é suscetível também de gerar descrédito, inclusive pela impunidade completa ou pela punição a longo prazo. Enfraquece-se, dessa maneira, o laço entre crime e castigo, socialmente tão significativo para o desestímulo de novas faltas.

Desse modo, a fragilidade dos direitos humanos coloca grande parte do investimento em favor da sua concretização nos planos da consciência moral e da criação e disseminação de novos valores sociais, o que remete à relevância da educação para os direitos humanos, tanto escolar como extraescolar, presencial como a distância. Sabemos da crise institucional da escola, em seu distanciamento da vida contemporânea, com o seu peso paquidérmico. Estaríamos, então, mais uma vez, no terreno difícil e dispersivo das grandes incertezas de valores e duvidosas efetividades? As perspectivas para o futuro seriam nebulosas senão sombrias?

\section{Rumamos para as distopias?}

Tantas e tão rápidas transformações mundiais podem nos levar à perspectiva dos direitos humanos como vencidos e não como vencedores, 
nada mais que belos valores esmaecidos pelo seu crepúsculo. Entretanto, embora seja difícil um balanço mundial das tendências do respeito aos direitos humanos, há evidências a colocar nos pratos da balança. Longe de esgotá-las, é indubitável que, à luz das contradições acima, aumentaram a exposição e a denúncia de violações. A opinião pública, ainda que segmentada em regiões e grupos sociais, é muito menos tolerante ao desrespeito e muito mais consciente em face da afirmação dos direitos humanos. Por outro lado, estabeleceu-se uma "cascata de direitos humanos" (Hunt, (2007), a começar pelos direitos sociais e econômicos, surgidos mais tarde nos Estados socialistas e do Terceiro Mundo (Delmas-Marty, 2004), prolongando-se pelos direitos das minorias, que, por sua vez, ainda segundo Hunt, estimularam novas e radicais ideologias das diferenças. Ademais, no curso desta cascata, surgiram direitos contraditórios, como, por exemplo, o direito a morrer com dignidade versus o direito absoluto à vida. Desse modo, constatamos a drástica expansão dos direitos humanos, suas maiores exposição e condenação moral e o aumento da criminalização das violações, inclusive pela constitucionalização de tais direitos no âmbito dos Estados nacionais. Se a coibição de comportamentos sociais depende de orquestrar desestímulos e sanções, é possível afirmar que o elenco de faltas condenáveis aumentou sensivelmente, o que pode ser também uma dificuldade adicional, enquanto se verifica um descompasso: parece mais frequente a condenação moral que a sanção judicialmente aplicada, o que em si também não é desprezível.

Por isso mesmo, ao analisar as mudanças de 1945 a 2000, Donnelly (2010), verificou que: a) no que tange às mudanças dos regimes internacionais de direitos humanos, se depreende o fortalecimento, maior promoção e monitoramento, além da fixação de normas globais dotadas de autoridade; b) quanto aos regimes regionais, houve avanços no europeu e no interamericano; c) no que concerne aos direitos específicos (mulheres, crianças, discriminação racial), se verificaram promoção, adoção de normas globais e fortes padrões, se bem que com exceções; d) no referente ao genocídio, chega-se à aplicação de normas em casos específicos. Portanto, apesar da lentidão, constatamos avanços.

Neste quadro, Delmas-Marty (2004) destaca que a heterogeneidade dos direitos do homem, de um lado, e a recomposição num direito dos direitos, 
de outro, constituem características de uma mutação que introduz o múltiplo no âmago da ideia de legitimidade. O direitos do homem poderiam ser, assim, o início do processo de recomposição num direito dos direitos, o que permitiria aproximar e não unificar os diferentes sistemas: "Aproximá-los numa harmonia feita tanto da subordinação deles a uma ordem supranacional como da coordenação deles segundo princípios comuns" (Delmas-Marty, 2004, p. 306).

Não é possível deixar de mencionar a alentada e controversa obra, porém muito bem documentada, de Pinker (2011). Sua tese central é que nossa era é menos violenta, menos cruel e mais pacífica. Dentre as evidências apresentadas, $15 \%$ da população pré-histórica teve morte violenta praticada por outra pessoa. Em contraste, na Europa, mesmo em períodos mais sangrentos, esta proporção é de aproximadamente 3\%. A taxa de homicídios no continente europeu hoje é de dez a 50 vezes menor que na Idade Média, o que o autor atribui em parte ao monopólio da força pelo Estado e ao processo civilizatório. Nesse sentido, o lluminismo levou a repelir formas de violência antes aceitas, como a escravidão, a tortura, o despotismo, o duelo e a violência contra os animais (algumas revoluções morais analisadas por Appiah (2010), como antes assinalado), na esteira de uma revolução humanitária. A ela seguiu-se, na segunda metade do século $X X$, a 'revolução dos direitos', fundamentada na repulsa à violência contra as crianças, mulheres, minorias étnicas, homossexuais e outros grupos. Além do Estado e do regime democrático, para isso contam o empoderamento da mulher, a expansão do comércio, a invenção da imprensa e a expansão dos meios de comunicação em geral. Todavia, os resultados não asseguram doravante o prosseguimento do declínio da violência, haja vista os choques civilizacionais, o terrorismo e as guerras resultantes de mudanças climáticas.

Por outro lado, apesar da contradição acima mencionada entre os direitos humanos internacionalmente estatuídos e a sua execução pelos Estados soberanos, Koo e Ramirez (2009) verificaram que o número de instituições nacionais governamentais de direitos humanos cresceu quase $50 \%$ em 1966-2004. Segundo ambos, as constatações contrariam as teses do declínio do Estado nacional na globalização, sendo estes peças chaves na concretização desses direitos. Os que ignoram este regime global caem na desgraça e na ilegitimidade, sofrendo, assim, pesadas sanções morais e outras. 
No campo não estatal, por sua vez, Salamon (2010) detectou a espetacular expansão da filantropia, do voluntariado e das organizações da sociedade civil nos últimos dois decênios. Em média as instituições não lucrativas empregavam nada menos que $5,6 \%$ da população economicamente ativa de 42 países (Portugal, 4,2\%; Brasil, 3,3\%). Quanto às organizações não governamentais internacionais, Turner (2010) constatou que elas aumentaram de 9.396 em 1980 para 27.472 em 2006. Embora só uma parte delas se dedique aos direitos humanos, trata-se de expressivo número. É claro que nem tudo são flores - e muitas das flores vêm a fenecer -, como concluíram Hasenfeld e Garrow (2012): nos Estados Unidos o ambiente institucional, econômico e político das organizações não lucrativas dedicadas aos serviços humanitários foi remodelado pela chamada ideologia neoliberal. Consequentemente, o discurso em favor da população socialmente mais vulnerável foi levado a mudar do âmbito nacional para o local, ao passo que se reduziu a visibilidade das suas necessidades. Ademais, foi refreada a motivação do setor no sentido de questionar o Estado e de efetuar mobilizações em favor dos direitos sociais.

Quanto à juventude, os mercados têm se esforçado em manter a juventude como consumidora passiva, enquanto Ihe falta trabalho. Entretanto, desde os anos 1980 vicejam os movimentos sociais, inclusive altermundialistas, com ativa participação da juventude. Como exemplo, em 2006-07 só em Medellín, Colômbia, havia 271 organizações juvenis ativas (Garcés Montoya, 2010). A "primavera árabe", as manifestações na Europa e na América Latina, em especial do Brasil e dos estudantes secundaristas e universitários do Chile, patenteiam que os jovens não parecem dispostos a circular como meros consumidores de centros comerciais e alienar a sua cidadania.

\section{Os direitos humanos e as leis do mercado}

É fato que, após a queda do muro de Berlim, a cidadania e os direitos humanos têm sofrido o vendaval da sociedade de consumo. Sem satanizar o sistema econômico, não são poucos os que reduzem as leis às leis de mercado, como se estas tivessem vida própria e se impusessem 'naturalmente' às sociedades, com grande eficiência, eficácia e efetividade. Com efeito, a denominada nova economia, pautada pela competição e pela 
liberdade como poder (por isso, de uns muito mais poderosos até outros desprovidos de poder), parece inscrever-se na História como o que Mauss (1969) chamava de fenômeno social total. Converter todas as oportunidades possíveis em formas de gerar dinheiro, invadir os espaços reais e virtuais com a publicidade, minimizar custos, maximizar lucros, reaplicar recursos, especular para obter mais e jogar nos cassinos financeiros sem ter certeza mínima sobre os resultados se tornaram marcas da paisagem de hoje, alcançando repercussões das quais talvez só escapem as poucas populações fora da economia monetizada. Daí emerge "a capacidade onívora dos mercados de consumo, sua fantástica habilidade de aproveitar todo e qualquer problema (...), todo protesto e todo impacto de 'força contrária' em proveito e lucro" (Bauman, 2013, p. 30). Não fosse a História fiada e tecida de contradições, seria possível acreditar na onipotência dos mercados. Com o "controle total dos canais de representação, divulgação e comunicação, as forças críticas e de oposição quase não têm escolha senão jogar de acordo com as regras do mercado, e assim (...) endossar e reforçar o domínio do mercado" (Bauman, 2013, pp. 30-31). A própria escola elabora novas imagens, como a empresa educativa e a McEscola, ao lado da escola-cidadã (Estêvão, 2012). Como outros sistemas econômicos, o capitalismo contemporâneo não é inédito, ainda que em parte original, na atitude de impor óculos ideológicos coloridos a todos os que lhe interessam. Ao contrário das suas origens, uma parte da ciência econômica se esforça em promover e justificar a intromissão do mercado em áreas que antes lhe eram negadas e em justificar normas segundo a moral do lucro e da eficiência, bem como seus efeitos deletérios, como se fossem perfeitamente 'naturais'. O ardor de certos discursos faz lembrar a defesa da monarquia absoluta como direito divino e a sacralização do corpo do rei. Como sabemos, a guilhotina na Revolução Francesa veio quebrar tragicamente aquela visão antes naturalizada. Não por acaso, os argumentos inerentes à lógica de mercado são admiravelmente desmontados pelo filósofo Sandel, sem guilhotina (a não ser as das gráficas, para cortar papel), em livros como O que o dinheiro não compra: Os limites morais do mercado (2012).

Sete anos após a queda do muro de Berlim e cinco antes dos atentados de 11 de setembro, Thurow (1996), em percuciente análise, afirmava que o capitalismo alcançara uma vitória de Pirro: demonstrara ser 
um sistema econômico mais eficiente e promissor, mas, ao espraiar-se pelo mundo, em contato com as mais variadas condições sociais e culturais, precisaria responder positivamente a expectativas muito diferenciadas. As exclusões têm limites e as reações à acumulação centralizada e à globalização homogeneizadora volta e meia explodem na realidade e na mídia. Com o aprofundamento da crise de legitimidade do capitalismo, por quanto tempo a coesão se manterá à custa da coerção? Porém, cabe indagar: na dinâmica do esquecimento e da lembrança intergeracionais e intrageracionais, as soluções passarão pelo Estado democrático e pela garantia dos direitos humanos? De qualquer modo, seria terrível maniqueísmo encarar os direitos humanos como deuses e o capitalismo contemporâneo como demônio. As realidades histórico-sociais envolvem labirintos e meandros tão contraditórios como a própria vitória de Pirro acima mencionada.

\section{É viável a educação para os direitos humanos?}

$\mathrm{Na}$ balança dos estímulos/desestímulos versus coerção e sanções, fica patente que ela pende para o primeiro lado, com resultados que não chegam a ser desapontadores. Se a consciência e a formação de atitudes e comportamentos assumem papel de tão magna importância, cabe uma preocupação compatível com a educação, não só a educação formal, escolar, mas aquela que se espraia por outros horizontes, mais informais e até certo ponto mais penetrantes. Isto logo pode suscitar conceitos como currículos, avaliação e professores, o que gira com frequência em torno do umbigo da escola. Antes disso, como lembra Serres (2013), é preciso indagar sobre quem educamos: o centro de gravidade não está em nós, mas no outro.

Ainda que ilustrativo, aqui cabe mencionar o Bernardo, menino de cerca de quatro anos, que estava, numa noite de 2008 (ano fatídico), num restaurante de Lisboa. Eis que súbito, em meio às tentativas dos dedicados pais no sentido de the ensinar boas maneiras, o Bernardo lança uma afiada pergunta, audível nas mesas vizinhas: "O que acontece com os meninos onde existe terrorismo?". Espectador da mídia na idade do infantário, ele havia sido atingido por imagens chocantes do que antes seria segredo: a violência e, adicionalmente, supomos, o sexo. E manifestou a capacidade de se colocar no lugar do outro, imaginando as dores de que padeciam seres humanos da 
sua idade, em condições tão difíceis. Em seguida à perplexidade dos pais, a saída encontrada pela mãe foi dizer-lhe: "Que bom, meu filho, que em Portugal não há terrorismo...”. Mas o Bernardo, com as sementes da compaixão, já se esboçava cidadão planetário e sentia em si a dor daqueles que estavam longe e dificilmente frequentariam um centro comercial de Lisboa, pleno de luzes, cores e produtos. Hoje ele deve ter cerca de nove anos de idade e auguramos que o Bernardo e seus pais não estejam sofrendo, como muitos, nas garras de outro terrorismo, o financeiro, que, sem bombas, espreme países inteiros para receber pagamentos de dívidas em prazos leoninamente fixados. $E$ que se sobrepõem às soberanias nacionais para ditar regras que 'equilibrem' as finanças (para isso, sim; para assegurar direitos humanos violados, não). Tais países têm território, população, riquezas naturais e outras, não desaparecem como uma empresa falida, mas, talvez por isto mesmo, são coagidos para a execução das sacrossantas leis do mercado, se preciso a ferro e fogo (domésticos, claro, pois o colonialismo deixou de ser rentável).

O episódio do Bernardo ilustra mudanças que envolvem as crianças desde cedo, no que Postman (1994) chamou de fim da infância, ao menos tal como esta foi gerada pela modernidade. Os antigos segredos se descortinam para elas por meio das tecnologias, alterando suas formas de pensar, sentir e agir, no rumo de um amadurecimento mais rápido, com o desenvolvimento da subjetividade. No contexto de vidas cada vez mais longas, abreviam-se a infância e sua inocência e ruma-se para uma longa adolescência, pontilhada de prontas decisões estratégicas em mundos diferentes, tais como os diferentes grupos de colegas, a família e a escola, no entrecruzamento de diferentes círculos sociais e culturais. Numa transição gradual, plena de nuanças, a adolescência transita quase disfarçadamente para a prolongada juventude, cuja moratória se dilata à medida que a economia reduz o trabalho e o emprego. Ao contrário de tantas sociedades tribais, o rito de passagem para a idade adulta não se expressa na ruptura entre formas de viver, mas em angustiantes idas e voltas, marcadas pela precariedade do trabalho e pela concomitância deste com o estudo, quando este não é atividade exclusiva. Pior ainda ocorre quando, em face da carência de oportunidades, a juventude nem trabalha, nem estuda, a chamada geração ni-ni. Nos filtros do esquecimento e da lembrança, que partes da bagagem cultural as novas gerações selecionarão? 
Nesse sentido, a escola para todos, flor encantada da modernidade, veio contribuir para o desenvolvimento da subjetividade e do protagonismo. Se bem que o mundo de hoje apresente um complexo mosaico de condições de vida e de escolaridade, a escola para todos produz várias contradições no horizonte de mudanças: de um lado, ela contribui para a subjetividade e o protagonismo; de outro lado, se cristaliza de tal modo que responder com incontáveis dificuldades às novas gerações. Entre estas, situam-se o ritmo lento, que conduz ao tédio; o conteudismo e a ênfase à memorização, em lugar da problematização e do desafio; a padronização, quando grande parte do mundo exterior multiplica suas diferenças, que, por sua vez, inevitavelmente retornam à escola; a grande preocupação com a vertente cognitiva do conhecimento, em detrimento da emoção, tão ligada aos interesses e à capacidade de aprender. Ainda ilustres desconhecidos, como compreender novos jovens, adolescentes e crianças, que, na interação com novos tempos e tecnologias, pensam, sentem e agem de modos em parte diferentes?

Se os direitos humanos dependem hoje fundamentalmente da consciência e do convencimento, desconhecer as novas gerações pode colocar em risco as modestas conquistas até o momento alcançadas, insuficientes, mas palpáveis. Isto se aplica tanto à educação escolar quanto à educação não escolar ou extraescolar. Na realidade, falta a muitos, como os educadores e não raro os familiares, o conhecimento de quem se educa; porém, a publicidade, voltada para os interesses do mercado, sabe muito bem identificar características desses grupos para fazer com que eles comprem mais, descartem mais e, cada vez mais cedo, contribuam para girar a máquina do consumo.

\section{Desafios para a educação escolar}

A educação escolar, que acompanha o ser humano por tempo crescente da sua vida, tem missão altamente relevante. Não sendo este um trabalho exaustivo, os pontos antes abordados implicam pelo menos três aspectos fundamentais:

a) A necessidade do exemplo vivo: O reconhecimento do valor educativo do exemplo é tão antigo como Platão. As gerações 
emergentes, com o seu protagonismo, carecem de experiências concretas da prática dos direitos humanos. Para elas a hipocrisia salta aos olhos e erode a legitimidade do educador e do processo educativo quando os valores proclamados contradizem os valores vividos e quando inspiradas palavras não se traduzem em atos. Assim, o clima escolar precisa antes de tudo construir uma cultura de paz e respeito aos direitos humanos, diante de uma gama tão rica de diferenças que já não se pode mais esperar serem assimiladas. O currículo é a vida, vivida na sala de aula, corredores, pátios, banheiros e outras dependências, dentro e fora da escola. Ultrapassa e transcende as peças burocráticas oficiais, inclusive a denominada grade (talvez melhor jaula) curricular. Esta não é missão fácil, pois construir uma cultura de paz, conforme o nome diz, implica cultivar - e a educação envolve paciência, perseverança e esperança, sempre acesas no longo tempo entre as incessantes semeaduras e colheitas. Sob este aspecto a escola e a vida precisam interpenetrar-se, mas a primeira não pode perder a sua identidade: suas tarefas e meios distam do imediatismo, da ansiedade e da descartabilidade da sociedade de consumo. Neste casamento a noiva nem pode ser inflexível, nem perder a sua identidade, sob pena de desvanecer-se. Quanto mais se analisam experiências bem sucedidas, mais parece evidenciar-se que a construção de um clima escolar respeitador dos direitos humanos depende menos das lideranças burocráticas e muito mais do brilho pessoal e grupal de lideranças carismáticas (Gomes \& Lira, 2010). Crianças e jovens, com a cabeça e os pés no futuro, não recepcionam bem os paquidermes burocráticos, mas se sensibilizam com o carisma pessoal, que toca corações e mentes, superando a estreiteza da racionalidade moderna. Isto implica virar a escola pelo avesso, este lugar de vários mundos, de várias racionalidades, com semântica e sintaxe especiais do exercício de direitos, não raro no contexto de democracias astênicas (Estêvão, 2013). É preciso fazer isto por meio das contradições de uma instituição historicamente violenta, hoje menos do ponto de vista físico, porém muito forte do ponto de vista simbólico. Isso significa 
instaurar ou reinstaurar a autoridade, legítima, para substituir o poder, ilegítimo.

b) Territorialidade curricular: Quando se passa das teias de relações interpessoais para as grades curriculares, verificam-se graves obstáculos para tratar de temas cuja complexidade se assemelha a uma praça, para onde convergem diferentes caminhos. O custo das formas quase onipresentes de organização escolar, em termos de tédio discente, mal-estar docente e fracasso escolar, supera largamente a acomodada simplicidade da associação professor turma - compartimento curricular. Apesar disso, os chamados temas transversais, como os direitos humanos, estão sujeitos a ser uma terra de todos e de ninguém. Nas hierarquias curriculares de poder e prestígio, tendem a ficar por último, quando não têm cumprimento meramente simbólico. A sociologia explica como se valoriza a distância dos componentes curriculares em relação à vida e à ação, bem como a abstração e especialização dos conhecimentos (Gomes, 2005). Todavia, os tempos de hoje, mais ainda os de amanhã, requerem pertinência, sentido, aplicação, coerência, abordagens integradas, praças do conhecimento, em vez de ruelas apertadas e profundas, carentes de sol, que a elas conduzem. Assim, a educação para os direitos humanos é apenas uma parte do desafio de novas epistemologias e novas formas de estruturar a escola, enquanto é tempo. Conforme Estêvão (2012), o currículo-cidadão, interdisciplinar, transcende o espaço da escola e acolhe a diversidade. Foca a justiça curricular, instrumenta a compreensão do mundo e da transformação social e propicia um ambiente favorável à autonomia do cidadão.

c) O protagonismo: Se conhecemos a quem educamos, é inútil persistir na aparente comodidade dos chamados métodos passivos. As metodologias, para fazerem sentido, precisam ser ativas e participativas, articulando teorias e condutas e estimulando os compromissos com práticas sociais (Tavares, 2010). A educação para os direitos humanos, assim como toda a educação escolar, não pode ficar inerme diante das mudanças dos alunos e dos tempos. Se, dentro e fora da escola, em grupos diversos, eles são 
chamados a enfrentar dilemas e tomar decisões de importância, longe dos adultos, não se pode negar que os currículos sejam pautados pelos desafios, pelo debate de dilemas, pela problematização, pelo estudo de casos e pela abertura de vias para a ação.

Se no processo histórico hoje não parecemos mergulhar nas distopias, embora estas sejam graves advertências, e constatamos que as utopias podem instigar a realidade a mudar em determinadas direções; se consideramos que os direitos humanos não são peças ornamentais, é preciso pôr mãos à obra, com coerência. É oportuno recordar o estribilho do discurso de Martin Luther King: "Eu tenho um sonho...". De fato, o seu sonho, após a morte, não se tem concretizado estritamente conforme a utopia: segue caminhos pedregosos, não raro se parece com miragens, mas o desenrolar da mudança é por ele poderosamente influenciado. Mais ainda, o processo continua, o rio prossegue meandroso, no seu perpétuo fluir, indicando que o seu sonho tem perspectivas de prosseguir na encarnação em atos e fatos históricos.

\section{Referências}

Appiah, K. A. (2010). The honor code: How moral revolutions happen. Nova lorque: W.W. Norton.

Bauman, Z. (2003). Modernidade líquida. Rio de Janeiro: Zahar.

Bauman, Z. (2008). Does ethic have chance in a world of consumers? Cambridge, Massachussetts: Harvard University Press.

Bauman, Z. (2013). Sobre educação e juventude: Conversas com Riccardo Mazzeo. Rio de Janeiro: Zahar.

Beck, U. (2009). World at risk. Cambridge, Reino Unido: Polity.

Castells, M. (2003). A sociedade em rede ( $7^{\mathrm{a}}$ ed.). Rio de Janeiro: Paz e Terra.

Castells, M. (2009). Communication power. Oxford: Oxford University Press.

Delmas-Marty, M. (2004). Por um direito comum. São Paulo: Martins Fontes.

Donnelly, J. (2010). Universal human rights in theory and practice ( $2^{\mathrm{a}}$ ed.). Cornell: Cornell University Press.

Estêvão, C. V. (2012). Direitos humanos, justiça e educação na era dos mercados. Porto: Porto Ed.

Estêvão, C. V. (2013). Democracia política, democracia escolar e educação para os direitos humanos. Educação, 36(1), 28-34. 
Garcés Montoya, A. (2010). De organizaciones a colectivos juveniles: Panorama de la participación política juvenil. Ultima Década, 32, 61-83.

Giddens, A. (1991). As conseqüências da modernidade. São Paulo: UNESP.

Gomes, C. A. \& Lira, A. (2010). Aprender a convivir: Cómo las escuelas hacen la diferencia. Revista Internacional Magisterio, 8, 40-45.

Gomes, C. A. (2005). A educação em novas perspectivas sociológicas (4ª ed.). São Paulo: EPU.

Hasenfeld, Y., \& Garrow, E. (2012). Nonprofit human-service organizations, social rights, and advocacy in a neoliberal welfare state. Social Service Review, 86(2), 295322.

Hunt, L. (2007). Inventing human rights: A history. Nova lorque: W.W. Norton.

Huxley, A. (1998). Brave new world. Nova lorque: Harper Collins.

Koo, J-W., \& Ramirez, F. (2009). National incorporation of global human rights: Worldwide expansion of national human rights institutions, 1966-2004. Social Forces, 87(3), 1321-1353.

Mauss, M. (1969). Oeuvres (v. 3). Paris: Éds. de Minuit.

Morin, E. (2001). Os sete saberes necessários à educação do futuro. São Paulo: Cortez; Brasília: UNESCO.

Orwell, G. (2011). 1984 (29a ed.). São Paulo: Nacional.

Pinker, S. (2011). Os anjos bons da nossa natureza: Por que a violência diminuiu? São Paulo: Companhia das Letras.

Postman, N. (1994). The disappearance of childhood ( $2^{\mathrm{a}}$ ed.). Nova lorque: Vintage.

Salamon, L. (2010). Putting the civil society sector on the economic map of the world. Annals of Public and Cooperative Economics, 81(2), 167-210.

Sandel, M. (2012). O que o dinheiro não compra: Os limites morais do mercado. Rio de Janeiro: Civilização Brasileira.

Serres, M. (2013). Polegarzinha: Uma nova forma de vier em harmonia, de pensar as instituições, de ser e de saber. São Paulo: Bertrand.

Tavares, C. (2010). Educar em direitos humanos, o desafio da formação dos educadores numa perspectiva interdisciplinar. In R. M. G. Silveira et al. (Eds.), Educação em direitos humanos: Fundamentos teórico-metodológicos (pp. 487504). Brasília: Presidência da República, Secretaria Especial dos Direitos Humanos.

Thurow, L. (1996). The future of capitalism: How today's economic forces shape tomorrow's world. Nova lorque: William Morrow.

Turner, E. (2010). Why has the number of international non-governmental organizations exploded since 1960? Cliodynamics, 1, 81-91.

Vidal, B. (2012). Les représentations collectives de l'événement-catastrophe: Étude sociologique sur les peurs contemporaines (Thèse de doctorat). Université Paul-Valery - Montpellier III, Montpellier. 


\title{
HUMAN RIGHTS: UTOPIA IN A DYSTOPIAN WORLD?
}

\begin{abstract}
This paper questions whether human rights are not part of a utopia that in the face of contemporary society challenges and dystopias is gradually disappearing. It finds that the historic trajectory of human rights includes periods of emergence and latency. An overview of the present situation reveals significant advances in relation to human rights norms, monitoring, denouncing and awareness, despite contradictions, in particular between norms and their enforcement in sovereign national States. The literature suggests that this progress is less a result of sanctions than of dawning awareness of human rights' moral legitimacy. Therefore, schooling and education in general have special significance. As regards schools, profound changes are needed: better knowledge of students, and establishing an ambience founded on actual example of human rights practice and respect. Curricula need to embrace interdisciplinarity and active methodologies to encourage students to take on a protagonist role.
\end{abstract}

Keywords

Human rights; Human rights education; Curricula; Modernity

\section{DERECHOS HUMANOS: ¿UTOPÍA EN UN MUNDO DISTÓPICO?}

\section{Resumen}

¿Serían los derechos humanos parte de una utopía de la modernidad, que se deshace ante las distopías y desafíos de la sociedad contemporánea? La historia de los derechos humanos comprende tanto períodos de emergencia como de latencia, pero la situación presente evidencia significativos avances en relación a las normas, monitoreo, denuncia y consciencia, a pesar de las contradicciones, particularmente entre las normas y su aplicación por los Estados nacionales soberanos. La literatura sugiere que tales avances se 
deben menos a las sanciones que a la consciencia en relación a la legitimidad moral, lo que destaca la importancia de la educación, sea escolar o extra escolar. Cuanto a la escuela, necesita de cambios profundos: conocer mejor a los estudiantes, así como construir un clima pautado por el ejemplo de la práctica y respecto a los derechos humanos. Los currículos necesitan de la interdisciplinaridad y de métodos para incentivar a los estudiantes como protagonistas.

Palabras clave

Derechos humanos; Educación para los derechos humanos; Currículos; Modernidad

Recebido em agosto, 2013

Aceite para publicação em outubro, 2013

\footnotetext{
Programa de Mestrado e Doutorado em Educação, Universidade Católica de Brasília, Brasil

ii Faculdade de Filosofia, Universidade Católica de Brasília, Brasil
}

Toda a correspondência relativa a este artigo deve ser enviada para: Cândido Alberto Gomes, SQS 303 - E - 601, 70336-050 Brasília, Brasil. E-mail: clgomes@terra.com.br 